\title{
Threats of increased spread of extremism in educational institutions of the Russian Federation in the context of the COVID-19 pandemic
}

\author{
Oksana Ishchenko* \\ Surgut State University, Lenina Av., 1, 628412 Surgut, Russia
}

\begin{abstract}
The COVID-19 pandemic, according to scientists and experts, was a major social upheaval that threatened to increase the spread of extremism among students. Analysis of open information sources shows that the growth of youth aggression in conditions of self-isolation and the increase in the amount of time spent on the Internet has contributed to the preservation of previous forms of extremist actions by children and adolescents, such as participation in destructive communities, causing harm to physical and mental health, preparing terrorist attacks in educational institutions. With the transition to distance learning, the mass disruption of classes was complemented, which can be considered in the context of preparation for extremist activity. All of this raises the question of the need for comprehensive research into the impact of the COVID-19 pandemic on youth extremism and the improvement of forms and methods of its prevention.
\end{abstract}

\section{Introduction}

The spread of extremism in the modern world is a serious threat to global and national security, and the greatest concern is the spread of extremist ideas among young people. A large number of studies have been devoted to identifying the causes of the spread of extremism among young people. Their authors draw attention to the fact that young people, due to their acute perception of the environment, are part of society in which radical views and beliefs more easily take root, and the accumulation and realization of negative protest potential occur quickly [1]. At the same time, the extremity of youth can manifest itself both in a socially positive and in a socially negative context. In the conditions of a stable society, it finds, as a rule, socially significant institutionally regulated forms, whereas in the conditions of social upheavals it often acquires extreme manifestations expressed in specific forms of behavior, which can range from aggressiveness, demonstrative deviations from the accepted norms to depression, depression, passivity [2].

The COVID-19 pandemic, which swept the world in 2020, was the greatest social upheaval of all, creating the greatest global security problem since World War II. Experts predict that the economic downturn caused by the pandemic will lead to an increase in

\footnotetext{
*Corresponding author: $\underline{\text { iovfu@yandex.ru }}$
} 
unemployment and poverty among young people. Harsh government actions and restrictions will backfire in the form of radical extremism and terrorism. In addition, the widespread dissemination of extremist ideas via the Internet is becoming a serious security threat. All of this together will make societies more vulnerable to all kinds of extremist propaganda [3].

The problem of increased propaganda by terrorist and extremist groups on the Internet was also reflected in the UN Counterterrorism Committee's report on the impact of the pandemic on counterterrorism and countering extremism. The paper stresses that the effects of the pandemic constitute a global generational crisis in which terrorists and extremists seek to exploit new problems to increase their numbers of supporters. At the same time, harsh quarantine measures increased security measures, restrictions on individual rights and freedoms cause a backlash in the form of the desire to counter it, including through extremist and terrorist actions [4].

\section{Materials and Methods}

The primary materials for the study of manifestations of extremism among students under conditions of the COVID-19 pandemic were obtained from an analysis of open information sources. A large amount of data was revealed when studying the materials of the weekly monitoring of extremist manifestations in educational organizations of the Russian Federation conducted by the Center for Prevention of Religious and Ethnic Extremism in Educational Organizations of the Russian Federation based on the search of information in the most popular media about any possible extremist actions among students in general and professional educational institutions [5].

Analysis of data from open information sources has been conducted since January 2020, when the World Health Organization declared an increase in the incidence of coronavirus infection an emergency. In March 2020, most educational institutions in the Russian Federation were switched to distance learning, which lasted until February 2021.

Limiting the format of full-time education has had a serious impact on the state of sentiment among students. The dramatic increase in the number of Internet users and the amount of time spent on the Internet has contributed to the proliferation of dangerous content. Teachers who worked with children remotely were no longer able to detect early signs of extremism. All this made the threat of increased penetration of extremist ideology in the youth environment more real.

In this regard, the analysis of open sources was aimed at identifying the main types of extremist manifestations in educational institutions, determining their changes in comparison with the period preceding the pandemic, and identifying the main sources of threats.

\section{Results and Discussion}

The coronavirus pandemic that began in March 2021 had a major impact on public sentiment. The threat of a new virus, constant fear-mongering in the media, and the severe limitations of the period of self-isolation created a surge of psychological problems. Chinese scientists, who studied this situation earlier than others, showed that the epidemic of coronavirus infection provoked a parallel epidemic of anxiety and depressive reactions, including in young people [6]. In addition, the demand for Internet resources has increased markedly in the context of the announced self-isolation. The switch of schoolchildren and students to distance learning has led to an almost constant stay of children and adolescents on the Internet. Live contact with friends and teachers was completely replaced by virtual contact, and the number of views on social networks increased, according to some reports, by almost a quarter. Restriction of walks, lack of opportunity to attend mass entertainment events, sports 
sections, other additional activities have transferred the whole life of students into an online format. Therefore, the three main factors influencing the formation of the teenager's consciousness: family, street, and school [7] are now joined by a fourth - the Internet.

Thus, it is young people who spend most of their time on social networks that are at risk of being drawn into the ranks of extremist communities and online radicalization. However, data from open sources show that with the transition to distance learning, the previously prevalent manifestations of extremism in educational institutions of the Russian Federation calls about the bombing of educational institutions - have sharply decreased. So, if before the introduction of distance learning only for the period from February 3 to February 10, 2020, the number of such messages was about 500, for the period from April 13 to April 20, 2020, not a single threat of mines in educational institutions was recorded [5].

With the return of educational institutions to full-time education, anonymous reports of bomb threats have resumed. In particular, on February 8, 2021, there was a surge of anonymous threats of mines at educational institutions, which resulted in the evacuation of several thousand schools in the country [5]. Experts predict a further increase in the number of such reports. Their presence indicates the possibility of shaping certain sentiments and the preparation of mass extremist actions through messages on the Internet.

At the same time, the switch to a distance-learning format created a new problem - the disruption of online lessons by pranksters. In the Telegram messenger and social networks Twitter and Vkontakte, schoolchildren from Russia, Ukraine, and the CIS countries created a number of large communities, where they posted access links to the classes [5].

Undoubtedly, disruptions of classes can hardly be classified as extremist acts, but they clearly show the readiness of a significant part of children and teenagers not to follow the established rules, but to support those who, in their opinion, express a kind of protest against the established system. Such young people may readily accept extremist ideas as well. Teachers themselves argue that the reasons for this behavior of students are the extremely low status of the modern teacher, who, in the eyes of many students and parents, is a powerless representative of the service sector. At the same time, in the media and social networks, other, often criminal images are formed, which become an example to follow, which significantly increases the risk of involving minors in destructive organizations [8].

An equally serious problem, also related to the Internet, was the increase in bullying and cyberbullying during the pandemic. Along with insults, threats, and profane language towards the victim, new forms, such as disrupting classes on behalf of the victim, have emerged. At the same time, the media reported that bullying often manifested itself in physical harm to children and adolescents. For example, in December 2020, a 12-year-old student was seriously injured by a classmate as a result of bullying. In February 2021, a video appeared on the social network VKontakte, showing a group of teenagers in Nizhny Tagil, Sverdlovsk Region, beating a school-age girl [5]. It should be noted that these manifestations of violence not only unite the group that commits attacks but also encourage the survivor of humiliation to join an extremist community, where such a person can feel that he or she is among their own [9].

In this case, open sources have also recorded other facts of the criminal activity of students. These include the attack on parents and niece by a teenager in St. Petersburg in 2020-2021, the knife wounds inflicted during an argument by an 8-year-old schoolboy to a classmate in Yuzhno-Sakhalinsk, the fatal wounds to mother by a 15-year-old in Balakovo, Saratov Oblast, and the stabbing by a seventh-grade student of a peer in a school in Bratsk, Irkutsk Oblast [5]. Such incidents indicate a high level of aggression among students, which many researchers attribute to the self-isolation of the pandemic period.

At the same time, according to data documented in the media, several prepared attacks on educational institutions were prevented in Russia in 2020. For example, in January 2020, three teenagers were detained in the Kostroma region who were preparing for a terrorist 
attack at their school. Their leader was a 15 -year-old boy who was into extremist ideas and had an interest in the Columbine movement. In February 2020, two teenagers aged 16 and 17 were detained in Kerch for preparing explosions in educational institutions. They called themselves followers of Vladislav Roslyakov, who in 2018 committed Russia's largest terrorist attack in an educational institution. In the spring of 2020 in the Tyumen region, a schoolboy was detained for planning to blow up his school on April 20, the anniversary of the mass shooting of students at the American Columbine School. In September 2020, a criminal case was opened against a teenager who was preparing for a terrorist attack in a school in the Krasnoyarsk region. In December 2020, an 18-year-old who was preparing a terrorist attack in an educational institution in Tula and a 17-year-old college student who was planning to prepare an explosion with an improvised bomb in Tambov were detained. In January 2021, two teenagers were detained on suspicion of preparing for a terrorist attack in a school in the Lyuberetsky District of Moscow Region [5].

In all of these cases, what stands out is the adherence of the teenage bombers to the ideas of the so-called "columbine". This is not a phenomenon today, as researcher A.R. Rico noted back in 2015 that a significant number of attacks on educational institutions in the United States in 2000-2015 had their perpetrators copying the Columbine school massacre [10]. However, it draws attention to the fact that there was no one in the educational institutions in the conditions of distance learning, so the experts' version of the mental problems of teenagers forced into self-isolation looks quite reasonable.

The other side of this problem was the growth of depressive moods, which caused an increase in the number of child and adolescent suicides. In particular, it was noted in the media that in January 2021, a 6th grader threw himself out of a fourth-floor window of a school in one of the schools in St. Petersburg. At the same time, 15-year-old schoolchildren committed suicide in Yekaterinburg and in the village of Shalinskoye in the Krasnoyarsk region. In February 2021 in Moscow, three 13-year-old girls who were trying to commit suicide simultaneously were rescued. In Samara, at the same time, the tragedy could not be prevented. Two 12-year-old girls fell from the sixteenth floor of an apartment building and died [5].

According to Professor Ilgiz Timerbulatov, Doctor of Medicine, Chief Psychotherapist of the Ministry of Health of Bashkortostan, the increase in suicides was directly related to self-isolation, distance learning, distance work of parents: "Families were like sardines in a tin, there were problems that did not exist, this is the effect of the closed collective. The second phase - exhaustion - has arrived. And this manifested itself in the form of depression, feeling of worthlessness, uselessness" [11]. However, the purposeful work of the creators of suicidal websites should not be overlooked, nor should the developed technologies of involving children and teenagers in suicidal groups.

In addition, the involvement of adolescents in extremist groups persisted during the pandemic. Particular attention is drawn to the commitment of a number of young people to the ideology of "AUE," which is on the list of banned extremist organizations. In January 2021, the prosecutor's office of Tatarstan announced the data according to which in 202094 teenagers were revealed in the republic who were members of the "AUE" movement. In the Kostroma region, a 17-year-old young man was brought to administrative responsibility for publishing materials containing "AUE" propaganda in VKontakte. In February 2021, a 17year-old schoolboy in Kemerovo was fined for openly identifying himself as a member of the banned organization "AUE" and actively publishing its symbols on his social networks [5].

The media also documented a number of young people belonging to nationalist groups that committed crimes motivated by ethnic and religious hatred, but which, like most extremist and terrorist groups, appealed to ideological or political goals that serve the "greater good" [12]. In particular, in the city of Omsk, three 17-year-old students beat several people 
on the grounds of their ethnicity in the fall of 2020. In the Bryansk region, in January 2021, a case was brought against an 18-year-old boy, who called for violence against representatives of several nationalities and planned to create an extremist community on this basis. In February 2021, a criminal case was opened in St. Petersburg against a 16-year-old girl who threatened a woman with a knife because of her ethnic and religious affiliation. Two 16-year-old boys were detained in Moscow for causing bodily harm to two migrants in the subway. In Voronezh, supporters of the neo-nationalist Ukrainian youth radical group "MCU" ("Maniacs: Cult of Killing") were identified, who posted extremist slogans on the city streets and filmed beating random victims on video [5].

Thus, analysis of open sources indicates that during the COVID-19 pandemic, the main manifestations of extremism among children and adolescents persisted, which raises the question of improving the effectiveness of their prevention.

\section{Conclusions}

1. The COVID-19 pandemic has created socio-economic problems that have increased instability in society. Under these conditions, the burden on the psyche of children and adolescents has increased, which was a factor contributing to the growth of extremist and terrorist manifestations in educational institutions.

2. The activities of extremist organizations have always been aimed primarily at young people. Extremist manifestations among students were there before, but the pandemic has increased the possibility of influencing children and adolescents through the Internet. Experts believe that the increased level of aggression in this environment is associated with a long period of self-isolation, distance learning, and a high degree of involvement in the virtual information space.

3. A new form of student activity has become a disruption of online classes during the distance learning period. Not being direct manifestations of extremism, but forming nihilism and impunity, they can contribute to the further involvement of children and adolescents in extremist organizations.

4. Analysis of open sources suggests that there are serious threats of increased extremism among children and adolescents under the influence of the COVID-19 pandemic. For now, however, conclusions can only be drawn from the current situation. The study of the long-term consequences of the COVID-19 pandemic and its further impact on youth extremism should be undertaken by scientists from various specialties: psychologists, educators, sociologists, and lawyers.

5. Threats of further strengthening the spread of extremism in educational institutions of the Russian Federation raise the question of the effectiveness of counteraction to this phenomenon. In the current circumstances, along with the traditional methods of force and education, emphasis should be placed on psychoprophylactic work.

\section{References}

1. V. K. Dovgyalo, Reporter of PSTU, Humanities and Social Sciences, 1, 21 (2018)

2. Yu. A. Zubok, V. I. Chuprov, Sociological Studies, 5, 37 (2008)

3. James K. Wither, Richard Mašek, Small Wars Journal (2020)

4. The impact of the COVID-19 pandemic on terrorism, counter-terrorism and countering violent extremism, The United Nations Security Council Counter-Terrorism Committee Executive Directorate (CTED), December (2020) 
5. Extremist Manifestations in Educational Institutions of the Russian Federation: Monitoring the Situation, https://cpeeo.ru/monitoring

6. M.Yu. Sorokin, E. D. Kasyanov, G. V. Rukavishnikov, O.V. Makarevich, N.G. Neznanov, N.B. Lutova, G. E. Mazo, Reporter of RSMU, 3, 77 (2020)

7. E. O. Kubyakin, Society: Politics, Economics, Law, 1, 38 (2010)

8. V. N. Zhadan, Legal Science, 8, 68 (2019)

9. Arne Roets, Arie W. Kruglanski, Malgorzata Kossowska, Antonio Pierro, Ying-yi Hong, Advances in Experimental Social Psychology, 52, 221 (2015)

10. A. R. Rico, Transformative Works and Cultures, 20 (2015)

11. R. Lyalin, Komsomolskaya Pravda, February 26 (2021) https://www.spb.kp.ru/

12. Richard Kirchner, Surveillance and Threat Detection (2014) 